\title{
Sir John Patrick Walsh KBE
}

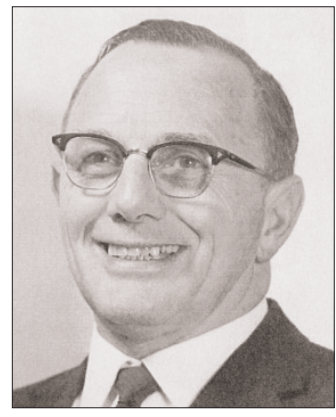

Professor J P Walsh, Dean of the University of Otago School of Dentistry from 1946 to 1971 died recently in Auckland, New Zealand. He was 92. It is impossible for one dentist to personally chronicle the achievements of this remarkable man. He studied dentistry and medicine in Australia after starting working life as an apprentice dental mechanic. He graduated with first class honours in dentistry in 1936 and followed this with a medical degree. By the end of WW II he was a medical officer in the Royal Australian Air Force and in 1946 he was appointed Dean at the school of dentistry in Dunedin, New Zealand. He transformed the school, broadening the scientific and clinical base, encouraging research and introducing a vigorous postgraduate programme. At the same time he was deeply involved in both national and international activities. In New Zealand he led an ultimately successful battle to fluoridate city water supplies, for which the related decline in dental caries speaks all. Internationally he was a key worker for dentistry with the World Health Organisation.

During his deanship Sir John persuaded a reluctant government to fund a major new building. This was opened in 1961 and was a revelation to me, moving into the "new" school for my final undergraduate year. Here was state-of-the-art dentistry with that marvel of the 1960's, high speed drills available in special circumstances. Few of my generation were aware of Sir John's role in this remarkable development. His involvement commenced while he was conducting discharge medicals in Melbourne in 1946. He observed the

\section{Bernard Greenfield}

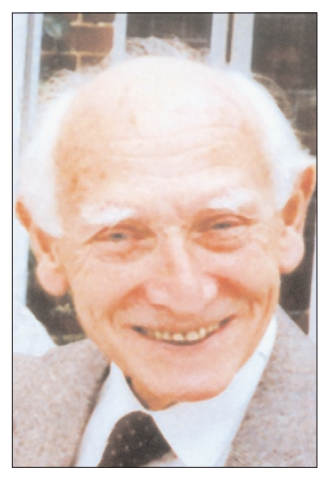

Bernard Greenfield died within a few weeks of his 89th birthday after suffering from Alzheimer's disease since June 2001.

He was born in Hackney and educated at the Central Foundation School, Cowper Street, EC2. He matriculated in 1931 and spent a year in the sixth form before leaving to work in a general engineering factory.

The long journey made studying for a BSc impossible and he was persuaded to change to dental surgery by his local dentist. He studied for 1st MB at Chelsea Polytechnic and passed after two terms. He completed his dental studies at the National Dental Hospital in Great Portland Street, passing the LDSRCS examination in February 1939.

He was commissioned into the RAF and served in North Africa, Sicily and India. After the war he practised in Hendon, Harley Street and Queen Anne Street. He went back to UCHDS to teach conservation, at the same time obtaining the BDS degree in 1949 and the FDSRCS in 1951. He had an enquiring mind that needed much intellectual stimulation and he found this in the Physiology Department of the Royal College of Surgeons where he developed a lasting interest in the electromyography of the muscles of mastication.

Bernard was a very popular teacher, he was deeply devoted and loyal to the students and never had a bad word to say about anyone.
It is impossible for one dentist to chronicle the achievements of this remarkable man...he is owed a great debt of gratitude by all those who benefited from his pioneering work with the high speed drill.

relation between the frequency of vibration applied to teeth and pain perception. From this base he sought to produce a rotary instrument with a frequency above the "discomfort level". By 1949, whilst transforming the Dunedin Dental School, Sir John had gained local support leading to the construction (and patenting) of a high speed air turbine handpiece little different from those of today. Details of

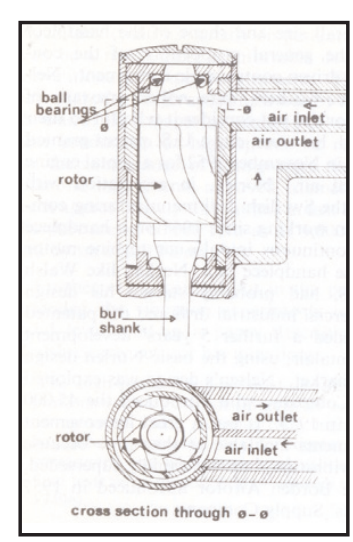
this astonishing development were published locally and are summarised in a British Dental Journal article (Br Dent J 1974; 136: 469-472), which included the 1949 patent drawing (left).

Sir John will be remembered with affection by all those he supported professionally but he is owed as great a debt of gratitude by all those who have unknowingly benefited from his pioneering work with the high speed drill.

Sir John's wife, Enid predeceased him and he is survived by his four children.

Alastair Stokes

\section{Bernard was a very popular teacher...He was deeply devoted and loyal to his stu- dents and never had a bad word to say about anybody.}

As a colleague he was stimulating and provocative in discussions with a very subtle sense of humour. He was fiercely loyal to UCHDS and to the old National Dental Hospital.

For relaxation Bernard enjoyed gardening, walking and camping. He shared these hobbies with his wife Shirley, and continued walking well into his later years. However his passion was work and on retirement from the Dental School in 1979 he continued as Honorary Research Fellow and was invited to continue his honorary work at the Eastman on the closure of UCHDS, until 1998.

He first met his wife Shirley at the Royal College of Surgeons. She worked as his dental nurse for 35 years and after he became ill in 2001 she nursed him devotedly through two very difficult years until a urinary infection led to his death in hospital on 9 July 2003.

We will remember Bernard as a very private, modest and unassuming gentleman who made a great contribution to dental science. He was much loved by his patients, his students and his many friends. He will be greatly missed by Shirley to whom our deepest sympathy is extended.

A G Alexander 